\title{
Espiritualidade, religião e bem-estar no enfrentamento de câncer colorretal: um
}

\section{estudo de caso}

\author{
Spirituality, religion and well-being facing colorectal cancer: a case study \\ Espiritualidad, religión y bienestar en el tratamiento del cáncer colorrectal: un estudio de caso
}

Recebido: 22/07/2021 | Revisado: 01/08/2021 | Aceito: 04/08/2021 | Publicado: 08/08/2021

Liliane Uberti Bertazzo

ORCID: https://orcid.org/0000-0001-8078-1422 Universidade Luterana do Brasil, Brasil E-mail: liliane.bertazzo39@gmail.com

André Guirland Vieira

ORCID: https://orcid.org/0000-0002-4487-6480 Universidade Luterana do Brasil, Brasil

E-mail: andre.vieira@ulbra.br

Jussara Pinheiro Sommer

ORCID: https://orcid.org/0000-0002-6485-4828 Universidade Luterana do Brasil, Brasil

E-mail: jussara.sommer@ulbra.br

\begin{abstract}
Resumo
O câncer é uma doença que causa uma ruptura na vida das pessoas e em seus projetos e na perspectiva de futuro. Temas como espiritualidade e religião têm sido cada vez mais estudados em pacientes com doenças graves. Assim, o objetivo deste estudo foi conhecer a percepção sobre espiritualidade e religião de uma paciente com diagnóstico de câncer colorretal. Este é um estudo de caso único, cuja metodologia foi escolhida por sua capacidade de nos permitir apresentar uma descrição detalhada de uma experiência de vida. A partir de uma análise de conteúdo, foram encontradas três categorias: revelação do diagnóstico, estratégias de enfrentamento e sentimentos diante da cura. Ser espiritualizada e religiosa faz parte da identidade pessoal da entrevistada. Ela afirma que é caridosa, bondosa e amável com todas as pessoas e declara que sua fé em Nossa Senhora de Caravaggio é uma história de devoção. Acredita que isto a ajudou a lidar com a doença e que influenciou em seu bem-estar durante e após o tratamento. Depois de curada do câncer, agradece as bênçãos recebidas e pagou a promessa que havia feito à Santa por tê-la curado da doença. Refere que sua fé a ajudou a superar a doença, pois nunca perdeu a confiança de que iria se curar e em função disso, passou a não ter medo de enfrentar a doença nem os momentos difíceis que viveu ao llongo do tratamento. $\mathrm{O}$ estudo nos permitiu uma melhor compreensão dos significados da espiritualidade e religião como um aparato psicoemocional coadjuvante no enfrentamento da doença.
\end{abstract}

Palavras-chave: Espiritualidade; Religião; Satisfação pessoal ; Oncologia.

\begin{abstract}
Cancer is a dzsease that disrupts people's lives and their projects and perspectives for the future. Topics such as spirituality and religion have been increasingly studied in patients with serious illnesses. Thus, the aim of this study was to understand the perception of spirituality and religion of a patient diagnosed with colorectal cancer. This is a unique case study whose methodology was chosen for its ability to allow us to present a detailed description of a life experience. From a content analysis, three categories were found: diagnosis disclosure, coping strategies and feelings towards the cure. Being spiritual and religious is part of the interviewee's personal identity. She claims that she is charitable, kind and loving to all people and declares that her faith in Our Lady of Caravaggio is a story of devotion. She believes that this helped her to cope with the disease and influenced her well-being during and after treatment. After being cured of cancer, she thanks the blessings received and paid the promise she had made to the Saint for having cured her of the disease. She says that her faith helped her to overcome her illness, to give her more tranquility in life and not to be afraid to face difficult moments and death. The study allowed us to better understand the meanings of spirituality and religion as a supporting psycho-emotional apparatus in coping with the disease.
\end{abstract}

Keywords: Spirituality; Religion; Personal satisfaction; Oncology.

\section{Resumen}

El cáncer es una enfermedad que provoca una ruptura en la vida de las personas y en sus proyectos y en la perspectiva del futuro. Emacomo la espiritualidad y la religión se han estudiado cada vez más en pacientes con enfermedades graves. Así, el objetivo de este estudio fue conocer la percepción sobre espiritualidad y religión de un paciente diagnosticado de cáncer colorrectal. Se trata de un único estudio de caso,cuya etologíam fue elegida por su capacidad para permitirnos presentar una descripción detallada de una experiencia de vida. A partir de un análisis de contenido, 
se encontraron tres categorías: divulgación del diagnóstico, estrategias de afrontamiento y sentimientos hacia la curación. Ser espiritualizado y religioso es parte de la identidad personal del entrevistado. Ella afirma que es caritativa, amable y amable con todas las personas y declara que su fe en Nuestra Señora de Caravaggio es una historia de devoción. Ella cree que esto la ayudó a sobrellevar la enfermedad e influyó en su bienestar durante y después del tratamiento. Después de que se curó de cáncer, ella agradece por las bendiciones que recibió y pagó la promesa que había hecho a Santa por curarla de la enfermedad. Ella dice que su fe le ha ayudado a superar la enfermedad, darle más tranquilidad en la vida y no tener miedo de enfrentar momentos difíciles y la muerte. El estudio nos permitió comprender mejor los significados de la espiritualidad y la religión como complemento psicoemocional para hacer frente a la enfermedad.

Palabras clave: Espiritualidad; Religión; Satisfacción personal; Oncologia.

\section{Introdução}

Todo adoecimento significa uma ruptura na vida nos projetos e na perspectiva de futuro. Quando o indivíduo está doente necessita buscar formas de enfrentamento de sua doença. Atualmente, temas como bem-estar espiritual e espiritualidade têm sido cada vez mais estudados em pacientes em geral e, especificamente, aqueles com câncer ou doenças graves. Este tipo de paciente tem reportado o enfrentamento deste momento por meio da espiritualidade (Turke et al., 2020). As alterações na integridade físico-emocional por desconforto, dor, desfiguração, perda da autoestima e mal-estar são geralmente relatadas por estes pacientes. Eles percebem uma profunda alteração na qualidade de suas vidas causada pela doença. Neste sentido, aspectos espirituais e religiosos poderiam ser estratégias auxiliares no enfrentando dos sintomas e estresse do tratamento dos doentes.

A espiritualidade faz parte do questionamento do ser sobre a sua existência. Diz respeito à sua relação com os valores que transcendem a vida material, seja qual for o nome que lhe atribua. Entretanto, o indivíduo não precisa aderir a uma determinada religião específica para usufruir de benefícios espirituais. Esta tem sido reportada como uma estratégia de enfrentamento de situações consideradas difíceis e impactantes, como o diagnóstico e tratamento do câncer, que produz diversos eventos adversos. Algumas das situações positivas associadas à espiritualidade são a melhora da saúde mental,redução do estresse e crescimento espiritual (Turke et al., 2020).

A espiritualidade é uma dimensão que faz parte do humano, independe da crença de cada pessoa. Nela há algo transcendente à realidade material, mesmo que muitas vezes não a reconheça. É algo que se desenvolve ao longo da vida, sendo vista como uma importante aliada, pois se conecta à busca por significado, propósito e transcendência da vida. Muitos indivíduos reconhecem na sua doença, com risco de vida, uma oportunidade de crescimento espiritual (Delgado-Guay \& Marvin, 2014). As religiões representam as respostas que a humanidade tem procurado dar a tais questões, a partir de um conjunto de práticas e crenças (Lima \& Machado, 2018). Tem sido utilizada como uma ferramenta de suporte na superação de problemas de saúde graves. A religião é uma construção do fazer humano, que possibilita a conceituação e a expressão da espiritualidade (Delgado-Guay \& Marvin, 2014).

A religião pode ser um apoio importante para pessoas com doenças graves como o câncer. Esta doença traz o estigma de que junto com ela vem uma sentença de morte, mesmo com todos os avanços científicos que contribuíram para melhores prognósticos e diminuição na taxa de mortalidade entre os pacientes. Os pacientes tem a ideia de que é uma doença dolorosa e que mata lentamente (Silva, Ruas, Barbosa, Soares \& Rocha, 2013). Assim, o diagnóstico de câncer impõe grande impacto emocional ao paciente e seus familiares.

O Instituto Nacional do Câncer (INCA) descreve câncer como um conjunto de mais de 100 doenças que têm em comum o crescimento desordenado de células que invadem tecidos e órgãos. $\mathrm{O}$ crescimento anômalo destas células tende a ser agressivo e incontrolável, determinando a formação de tumores malignos que podem se espalhar por distintas regiões do corpo. As causas do câncer são variadas, podendo ser externas ou internas ao organismo (Inca, 2014). 
Nesta perspectiva, é normal o ser humano sentir-se vazio e desesperado diante de uma doença que ameaça a sua vida, acreditando ser incapaz de encontrar significado para seguir em frente. Um estudo realizado em 2017 apresentou que a espiritualidade, diante de situações adversas como uma doença grave, traz conforto, bem-estar, segurança, significado e força para enfrentar as dúvidas, o sofrimento, a preocupação e medo (Siqueira, Cecagno, Medeiros, Sampaio \& Rangel, 2017).

Para lidar com o processo de adoecimento, pacientes com diagnóstico de câncer colorretal utilizam algumas estratégias que transcendem as questões de enfrentamento tradicional da doença. Dentre elas, se encontram a espiritualidade, o suporte familiar, apoio social, a reflexão sobre o problema, a adoção de medidas de autocontrole e as atividades relacionadas ao autocuidado (Oliveira, Oliveira \& Schnaider, 2012).

Diante do processo de adoecimento e da internação, a família depara-se com dificuldades no enfrentamento da situação. O momento vivenciado pelo paciente e sua família constitui-se de estresse permanente, sofrimento emocional, elevação da ansiedade, medo do desconhecido e apreensão quanto às decisões e situações a enfrentar. Considerando o exposto, fica evidente, que o sentimento de inutilidade, desgosto, depressão, perda da autoestima, status social e libido, além de reforçarem as alterações na dinâmica familiar, causam impacto psicológico, nutrem a fantasia de que perderão sua capacidade produtiva, levando-os a exteriorizar sentimentos como tristeza, ódio, repulsa e medo (Cascais, Martini \& Almeida, 2007).

Este estudo tem por objetivo conhecer a percepção de uma paciente com diagnóstico de câncer colorretal sobre como a espiritualidade e a religião ajudaram-na a lidar com a doença e como influenciaram em seu bem-estar e na cura da doença. Para tanto, estudamos o caso de Rosa, uma mulher idosa, que vivenciou o tratamento de um câncer colorretal, e que sendo uma pessoa profundamente religiosa, utilizou a espiritualidade como estratégia de enfrentamento da sua doença.

\section{Metodologia}

O presente estudo utilizou um delineamento de estudo de caso único (Yin, 2001). A escolha por esta metodologia ocorreu em função de que este tipo de proposta tem a capacidade de relatar de forma abrangente uma experiência de vida, permitindo que os elementos espiritualidade e religião possam ser estudados de forma mais profunda e detalhada. O caso escolhido deve sugerir a respeito do todo e auxiliar a entender como casos semelhantes podem se comportar. Esta investigação deve estar contextualizada no tempo e no espaço para que se possa entender melhor suas inter-relações (Ventura, 2007).

A participante desta pesquisa é uma mulher de 63 anos de idade, com histórico de câncer de colorretal há cinco anos. Foi escolhida por conveniência, em função de a pesquisadora ter acompanhado o seu processo de tratamento e a coleta dos dados foi realizada em maio de $2021 \mathrm{em}$ sua residência (local escolhido pela entrevistada). A pesquisadora já havia tido contato com a entrevistada em função do tratamento realizado em serviço de saúde no qual trabalhava como enfermeira. Assim, após o contato telefônico, foi realizada visita domiciliar para a realização da entrevista. A entrevista durou em torno de três horas e teve como questões norteadoras: como a espiritualidade e a religião ajudaram a lidar com o Câncer colo retal e se esses fatores influenciaram no seu bem-estar. Foram respeitadas as condições de privacidade para garantir a espontaneidade por parte da entrevistada, e adotados todos os cuidados de biossegurança, uma vez que a entrevista foi realizada em plena Pandemia de Covid-19. Foi utilizado o telefone celular como gravador e após a realização da entrevista, esta foi transcrita em documento em formato Word pela própria pesquisadora.

Para a análise dos dados foi utilizada a Análise de Conteúdo de Bardin (2011), que permite qualificar as vivências do sujeito, bem como suas percepç̃os sobre determinado fenômeno. O trabalho de análise passa por três fases: pré-análise dos dados, etapa na qual se sistematiza as ideias iniciais e relaciona-se com o referencial teórico para estabelecer indicadores que auxiliem na interpretação dos resultados; organização dos dados é o momento em que se divide o texto em unidades de registro para se agregar em temas e depois em categorias; e tratamento dos dados, fase de ressaltar os aspectos mais importantes 
contidos na entrevista. Na análise da narrativa, foram organizadas três categorias que emergiram do discurso. São elas: 1) A revelação do diagnóstico; 2) estratégias de enfrentamento; 3) sentimentos diante da cura.

A pesquisa foi conduzida dentro dos padrões éticos exigidos pela Resolução $N^{\circ}$ Resolução $N^{\circ}$ 510, de 07 de abril de 2016 do Conselho Nacional de Ética e Pesquisas, tendo sido aprovada pelo CEP sob o número 4.623.019. Somente após este parecer e a assinatura do Termo de Consentimento Livre e Esclarecido, foi realizada uma entrevista.

\section{Resultados e Discussão}

\subsection{A história da rosa e de sua doença}

"Rosa" possui 63 anos, cor branca, residente em município da região da Serra Gaúcha, Rio Grande do Sul. Nasceu no interior do Estado, na zona rural, sendo a nona filha de nove irmãos. É a mais jovem deles, e trabalhou na roça até os seus 17 anos. O seu pai faleceu aos 70 anos de infarto agudo do miocárdio e sua mãe com 65 anos com história de câncer de pâncreas.

Ela revela ser praticante da religião Católica Apostólica Romana, realizou catequese, crisma e frequentava a missa todos os domingos desde pequena. Na casa em que nasceu e cresceu havia uma capelinha de Nossa Senhora de Caravaggio, a Santa padroeira da família, local no qual ela aprendeu a orar e crer nesta entidade.

Aos 18 anos mudou-se para a cidade, onde começou a trabalhar em uma empresa de molduras. Trabalhou neste local por toda sua vida até se aposentar. Aos 25 anos casou-se, aos 28 engravidou e ocorreu um aborto no quarto mês de gestação. No ano de 1991, teve uma segunda gestação, e deu à luz a um filho homem, por cesariana, não teve gestações posteriores.

Em relação aos antecedentes pessoais relatou menopausa aos 55 anos. Nega cirurgias anteriores á doença, nega hipertensão arterial e diabetes. Quanto à rotina alimentar, relata que nunca realizou dieta balanceada, não praticava esportes, não consultava o médico regularmente.

Com histórico de câncer colorretal há cinco anos, relata que a partir da descoberta do diagnóstico, realizou tratamento com quimioterapia e radioterapia, fez uso de bolsa de colostomia por cerca de um ano. Durante este período houve formação de hérnia abdominal devido ao uso desta bolsa.

Relata que começou com queixas de dor abdominal, em fossa ilíaca direita, de forte intensidade, contínua, em pontada, iniciada dois meses antes da consulta, acompanhada de mudanças de hábito intestinal. Este constipado, com piora neste período, esteve associado à dor abdominal em cólica.

Realizou uma colonoscopia que diagnosticou uma lesão vegetante e estenosante em reto alto, impedindo a progressão do aparelho. A biópsia mostrou tratar-se de um adenocarcinoma colonico. Houve ainda crescimento de tumoração em tomografia de fossa ilíaca direita, anorexia e perda de peso de cerca de $6 \mathrm{~kg}$ no período.

A paciente relata que desde criança é praticante da religião católica e devota de Nossa Senhora do Caravaggio. Rosa credita 90 por cento da sua cura à fé em Nossa Senhora de Caravaggio. Após tratamento regular que realizou durante todo o período da doença, pensa que a fé foi fator primordial no processo de enfrentamento e cura.

A entrevistada conta que sua história de devoção a Nossa Senhora de Caravaggio começou na infância. A família dedica-se a espiritualidade e a religião católica. Aponta que o mês de maio é dedicado a comemoração à Santa, e participa em várias romarias nesses momentos. Rosa diz ter ido a pé de sua cidade até o Santuário de Nossa Senhora de Caravaggio. Ela conta que todos os anos desde que casou, há 30 anos, faz promessa à Santa, pedindo para ela tudo o que necessitava e diz acreditar que sempre foi atendida.

Rosa informa durante a entrevista, que ser espiritualizada e religiosa faz parte de sua identidade pessoal, e aumenta sua satisfação pessoal, afirmando que é caridosa, bondosa e amável com todas as pessoas. Declara que sua fé em Nossa Senhora de Caravaggio é uma história dedevoção. 
Após curada do câncer, ela afirma que só tem a agradecer as bênçãos recebidas. Pagou a promessa que havia feito à Santa por tê-la curado da doença. Em seu relato indica que a fé, a espiritualidade e superação são palavras que fazem parte de sua vida. Sua fé a ajudou a superar a doença e a lhe dar mais tranquilidade. Também auxiliou a não ter medo de enfrentar os momentos difíceis e a morte, de acordo com as falas a seguir:

\section{[...] a espiritualidade me dá tranquilidade, eu não tenho mais medo do sofrimento e da morte [...]}

[...] a morte só vem quando é chegada a hora, e sempre acreditei que minha vida seria longa, isso foi minha fé em Nossa Senhora de Caravaggio e espiritualidade quem me guiaram [...]

Do relato de Rosa foram definidas três categorias organizadoras de sua narrativa. São elas: a revelação do diagnóstico, estratégias de enfrentamento e sentimentos diante da cura.

\section{Revelação do Diagnóstico}

A confirmação do diagnóstico de câncer é um momento difícil de ser enfrentado pelo sujeito, pois passa a conviver não apenas com o estigma da morte que o câncer culturalmente carrega, mas também com os efeitos colaterais do tratamento. Este momento é dos mais difíceis deste processo, pois o câncer é uma doença que ainda hoje é relacionada à dor, ao sofrimento e à degeneração, igualando-se a um atestado de óbito. Além disso, esta doença ainda passa pelo estigma de que o processo de adoecimento é sempre um processo bastante doloroso até a morte chegar (Costa et al., 2016).

Rosa refere sua tristeza frente ao diagnóstico de câncer, principalmente porque em função dele teve necessidade de mudanças do seu estilo de vida. Relata ter desejado conhecer seu estado clínico e a verdade sobre a evolução da doença e sobre possíveis tratamentos a serem priorizados. Para Rosa foi um choque receber o diagnóstico de câncer. Não acreditava que poderia acontecer com ela, refere que "senti a morte muito próxima de mim, nunca me imaginei com esta doença".

A entrevistada revela: [...] o diagnóstico foi terrível, o mundo acabou para mim. Chorei muito, me preocupei muito, já comecei a me
imaginar sem cabelo, mas mesmo assim eu preferi saber da gravidade de meu estado [...]

Rosa aponta em suas falas que quando soube da doença, ficou desnorteada, que a notícia veio como uma bomba em sua cabeça. Achava que ia morrer e que isto aconteceria rapidamente, de uma hora para outra. Em suas falas diz que não queria morrer, pois amava muito as pessoas e queria mais tempo para conviver com elas. Entretanto, como era uma pessoa de fé, reforçou suas orações à Nossa Senhora do Caravaggio pedindo que pudesse se recuperar, conforme fala a seguir:

\section{[...] rezei por horas em frente à imagem de Nossa Senhora de Caravaggio, de joelhos, durante os banhos, deitada em} minha cama sem conseguir dormir [...]

Durante um mês de tratamento, viajava para Porto Alegre todos os dias. Relata que isto era muito exigente, pois apresentava muitos vômitos, enjoava, tinha dores,

[...] mas mesmo assim nunca perdi a esperança e a fé, em cada curva, em cada lugar que eu passava eu segurava minha imagem de Nossa Senhora de Caravaggio na mão [...].

Conforme o relato Rosa nunca perdeu a fé em Nossa Senhora do Caravaggio nem em Deus. Sabia que se orasse com fé, conseguiria o conforto necessário para enfrentar a dor, a doença e o tratamento. Segundo estudo realizado com pacientes 
oncológicos, as reações provocadas pelo diagnóstico de câncer foram relatadas pelos seus entrevistados como sendo um choque muito grande e vindo com ele o medo de morrer. Para os pacientes, o estigma de que é o câncer mata é muito forte. Assim, frente ao diagnóstico, esses pacientes entendem que a morte está muito próxima (Aquino \& Zago, 2007).

O Câncer ainda hoje é uma doença que desencadeia uma série de reações devastadoras no sujeito, tanto no corpo físico como nos aspectos emocionais, provocando conflitos existenciais, desequilíbrios, medo e insegurança (Penna, 2004). Seu diagnóstico é encarado, na maioria das vezes, como uma sentença de dor, sofrimento e morte (Venâncio, 2004). Diante do desgaste físico a que o paciente oncológico é submetido em função dos procedimentos terapêuticos invasivos e, muitas vezes mutilantes, ele é acometido por sentimentos de raiva, perda de controle de sua vida, pena de si mesmo (Porto, 2004). Assim, o diagnóstico desencadeia, além da doença e de seus efeitos físicos, várias reações emocionais que se não forem observadas poderão colocar o paciente em situação ainda mais vulnerável, pois podem afetar suas atividades cognitivas e seu comportamento.

O câncer colorretal é uma doença com manifestação clínica tardia, sendo diagnosticada em etapa avançada, sendo a média da idade de diagnóstico em torno dos 63 anos e a prevalência um pouco maior em mulheres (Leme, Pereira, Coutinho, Assis \& Leme, 2007). É considerada a neoplasia maligna mais comum do tubo digestivo, e teve sua incidência aumentada nos últimos anos, principalmente em áreas consideradas de baixo risco (países em desenvolvimento). Vários fatores podem estar envolvidos, como o envelhecimento da população, sedentarismo e hábitos alimentares pouco saudáveis. Estima-se em cerca de meio milhão o número de óbitos por esta doença a cada ano, com tendência a queda na mortalidade nos últimos anos (DuarteFranco \& Franco, 2004).

\section{Estratégias de Enfrentamento}

Apesar de tantas vivências negativas, experimentadas por Rosa, ela refere à importância do apoio familiar e sua amorosidade, sua religião e sua espiritualidade. Reconhece e agradece muito o cuidado recebido dos familiares e amigos. O tratamento oncológico é "invasivo e doloroso", o que a deixou muito enfraquecida e emocionalmente frágil. As falas a seguir reforçam como para Rosa foi importante a companhia e apoio de pessoas próximas.

[...] meи marido fez de tudo, coitado. Se pudesse trazer o céu para mim, ele traria. Ele fez tudo o que eu pedi, rezou junto comigo, assistia a missa junto comigo, me fazia sentir bem melhor apesar de tudo [...].

[...] o amor das pessoas vale a pena a gente passar por tudo isso, minha família, meu esposo e filho, minha nora, todos os amigos, rezaram por mim, pessoas espiritualizadas e abençoadas [...].

Foi fundamental a escuta, a parceria da família e o apoio de amigos próximos que a auxiliaram na elaboração de sentimentos e fantasias relacionadas à doença, bem como a participação ativa no tratamento. Fica evidente nas falas de Rosa que a religião foi um suporte para a convivência com a doença, pois proporcionou maior equilíbrio frente às adversidades $\mathrm{e}$ dificuldades enfrentadas, como descrito a seguir:

[...] Chorei muitas vezes no ombro de meu esposo e de meu filho, eles rezavam comigo para me acalmar, foi por eles que persisti na minha fé e luta, Nossa Senhora de Caravaggio faz mais espirituosa [...].

Rosa deixa muito evidente a necessidade de sentir-se acolhida e protegida pela família, conforme relata:

[...] Eu fazia caminhadas com meu esposo, lavava roupa, passava, fazia comida, fazia tudo ali, meu filho ajudava a fazer pão, e agora não faço mais nada, a minha sorte é ter eles comigo sempre [...]. 
[...] o meu marido é uma babá que cuida de mim [...]. Eu amo ele [...].

Para Rosa a família e amigos foram essenciais na sua recuperação e qualidade de vida. Ela aponta que é indispensável haver compreensão sobre o dia a dia de pacientes que passam por situações como a dela, pois isto ameniza o sofrimento e auxilia a encontrarem novos caminhos.

Relata que apesar de estar doente, sabe que é muito amada por seu filho, marido e por Deus, e isto, para ela, faz toda a diferença para o enfrentamento da doença, conforme aparece nos relatos a seguir.

[...] Deus me deu uma família maravilhosa, e sempre mantive a fé e a oração junto com a gente, meu esposo falou que me amava todos os dias, isso me manteve forte pra lutar contra o câncer [...].

[...] Com quem eu mais contei no momento da doença foi com a minha família! Sem ela e sem minha espiritualidade não resistiria $[\ldots]$.

Percebe-se que apesar de existirem várias formas de enfrentar as doenças crônicas, elas estão sempre relacionadas ao estilo de vida e ao momento que o indivíduo está passando. No caso de Rosa, foi marcante a presença da espiritualidade como uma estratégia utilizada por ela para o enfrentamento da doença. Nas falas de Rosa isso fica muito evidente, conforme aparece a seguir.

[...] sempre fui uma mulher de muita fé, muito religiosa, muito espiritualizada sei que isso me ajudoumuito na minha cura, fui criada assim [...]

Apesar de tantas vivências negativas, durante a entrevista emergem relatos sobre a importância da espiritualidade e da religião para encontrar respostas ou conforto para suas dúvidas e anseios. A fé em um Deus, em um ser supremo, foi um sentimento fundamental para a paciente. É importante reconhecer que, em momentos de sofrimento, os pacientes oncológicos podem recorrer à fé e às crenças religiosas como fonte de alívio e conforto (Aquino \& Zago, 2007).

Existem diferentes estratégias de enfrentamento a serem utilizadas, como forma de auxiliar o doente na maneira de lidar e compreender a doença. A espiritualidade é uma delas e os pacientes com câncer referem rezar e fazer promessas como maneiras de expressar sua fé em Deus, na tentativa de melhor se ajustar à situação de doença. A espiritualidade compreendida como algo inerente ao ser humano, refere-se à busca humana de sentido para a vida, por meio de uma relação consigo mesmo, com os outros e com o divino. Pode ser o que conforta e fortalece os indivíduos para que continuem a viver e pode envolver uma figura divina ou uma força superior (Pinto, Caldeira \& Martins, 2012).

Observa-se nas falas a seguir que a religião, para a entrevistada, está ligada a comportamentos saudáveis e a valores humanitários:

\section{[...] sempre acreditei em Deus e fui crente em Nossa Senhora de Caravaggio, minha fé me manteve fortee paciente $[\ldots]$}

Embora nem todas as pessoas com afiliação religiosa sigam todas as diretrizes relacionadas com a saúde propostas pela sua crença, não há dúvida de que se possa esperar que, na média, as pessoas que relatam uma identidade religiosa têm mais probabilidade de seguir as regras da sua religião do que as pessoas que relatam não ter nenhuma afiliação religiosa.

Conforme relatado por Rosa, ser religiosa fez muita diferença para enfrentar o processo de câncer, evidencia-se nas falas a seguir: 
[...] sempre fiz promessas pra minha Santa, sempre fui ás missas no domingo, aprendi que devemoscuidar do corpo e da alma, pois minha saúde depende de eu estar bem com Deus [...].

A pessoa que convive com câncer vive simbólica e corporalmente processos contraditórios de saúde e doença, que exigem se perceber e se constituir como protagonista na direção da construção de seus projetos de vida. Esta situação de contradição é complexa, já que o paciente se encontra o tempo todo diante do fenômeno de saúde e doença, e estas situações geram sentimentos de desesperança, perda de controle e perda de autoimagem, que são aumentados pela destruição de valores espirituais e culturais (Salazar \& Motta, 2001).

Há um período significativo em que o paciente oncológico reflete sobre seu futuro, seus anseios, sua vida pessoal, conjugal e sua religião. Emergem muitas dúvidas e medos com relação ao amanhã. Por se tratar de uma doença onde o portador torna-se um alvo de penúria, o câncer desperta sentimentos de frustração, raiva, vergonha, ansiedade, pesar, incerteza, medo e a expectativa da morte no paciente (Silva et al., 2013). Neste momento, o medo da morte fica evidente, conforme observado nas falas de Rosa. Para ela, sem a espiritualidade ela não resistiria a este momento.

[...] Muitas vezes durante meu tratamento senti medo de não estar viva no próximo dia, no próximo ano.O meu medo de não conhecer meus netos, ou de não envelhecer ao lado de meu esposo [...]

\section{[...] nesses momentos me senti tranquila por ser tão forte na fé e na espiritualidade [...].}

É possível perceber nas falas de Rosa o quanto sua vida espiritual foi fundamental para fortalecê-la e a impulsionar a seguir adiante com o tratamento do câncer. A mudança em seu estilo de vida com a doença foi um fato concreto, pois deixou de participar de algumas atividades do cotidiano que lhe eram importantes, como ir à missa. Aponta que o único caminho saudável é a pessoa se conformar com o presente a ser vivido, e não perder a esperança.

\section{[...] mesmo eu não podendo ir à Igreja rezar a missa, rezar o terço, eu nunca perdi a fé [...].}

[...] durante o tempo em que usei colostomia não saía de casa, pois além do constrangimento, achavafalta de respeito sair com aquela bolsa[...]

[...] minha vida se resumia a comer, dormir e rezar, assim o que me ajudou foi minha fé, ela me deuvontade de ser curada $[\ldots]$

[...] Fé é tudo! Não consigo me imaginar sem a fé nesse meu Deus que tudo pode e em Nossa Senhora deCaravaggio. Confio nela desde pequena e ela me ajuda sempre [...].

Dentro da categoria definida como Estratégias de enfrentamento, a família, a espiritualidade e a religião foram os suportes nos quais Rosa se apoiou. Foram eles que a auxiliaram para manter os cuidados necessários e exerceram influências sobre a sua saúde física, psíquica, social e espiritual. Neste contexto, o envolvimento das pessoas da família com a paciente, assim como sua fé e envolvimento religioso ajudaram no enfrentamento da doença.

Esta é uma forma de enfrentamento, presente mesmo quando outras atividades já estão sendo realizadas, tendo em vista que ajuda a amenizar a dor e o sofrimento provocados pelo impacto do diagnóstico (Oliveira et al., 2012). Nesta perspectiva, a espiritualidade é um fenômeno que funde corpo e mente e dá significado, força e fé na jornada do câncer (Gifford, Thomas, Thomas, Grandpierre \& Ukagwu, 2019). O desenvolvimento espiritual, independente, de sua configuração cultura ou classe social, tem sua importância na vida de toda a pessoa (Balboni, Puchalski \& Peteet, 2014). Esta busca de significados para a vida é uma forma de transcendência, que busca uma conexão com algo que vai além de si próprio. Necessariamente, a pessoa não precisa ter uma religião para poder fazer esta transcendência, pois está relacionada a um 
conjunto de crenças e práticas que caracterizam um grupo que procura dar um significado às situações vivenciadas (Costa et al., 2016).

A espiritualidade se interconecta com raízes e culturas tradicionais, funde o corpo e mente, e dá significado, força e fé na jornada da vida. Quando a pessoa encontra-se adoecida, auxilia no enfrentamento da doença. O desenvolvimento espiritual faz parte do ser humano independente de sua identificação cultural, religiosa ou qualquer outra questão (Gifford et al., 2019).

O bem-estar espiritual tem mostrado efeitos positivos em pacientes com câncer, sendo um importante componente de saúde e contentamento (Balboni et al., 2014). A espiritualidade fortalece a fé e, com isso, propiciar pensamentos mais otimistas, possibilitando amenizar a tensão interna decorrente da fonte estressora (Costa et al., 2016).

A participação como membro de religiões está fortemente associada a um comportamento saudável. Várias religiões ditam comportamentos com relação à saúde, à doença e à morte. Para as pessoas que seguem uma religião, muitas das doutrinas ou ensinamentos de sua fé oferecem orientação moral e prática com relação a como promover, conservar ou recuperara saúde ou o bem-estar físico e emocional. Além das regras presentes nos ensinamentos religiosos, a consideração do corpo humano como sagrado, frequentemente presente nas mesmas, leva o crente a valorizar os cuidados de saúde (Vasconcelos, 2010).

Ressalta-se que todo adoecimento significa uma ruptura na vida, nos projetos, na perspectiva de futuro; dessa forma, o indivíduo necessita buscar formas de enfrentamento para essa nova situação. É um processo inserido na história de vida da pessoa que adoece e, portanto, está vinculado a uma dinâmica em que os pensamentos, emoções e ações atreladas a sua condição biopsicossocial e espiritual vão permear as possíveis maneiras de lidar com o agravo à saúde (Costa et al., 2016).

A escuta e a parceria da família tornam-se fundamental para auxiliar o paciente na elaboração de sentimentos e fantasias relacionadas à doença, como também na participação ativa do tratamento. Todo adoecimento significa uma ruptura nos projetos devida e na perspectiva de futuro. Desta forma, o indivíduo necessita de suporte social e apoio familiar para fazer o enfrentamento desta nova situação. Este processo é exigente, pois o paciente e sua família passam por uma dinâmica em que os pensamentos, emoções e ações atreladas a sua condição biopsicossocial e espiritual que vão permear as possíveis maneiras de lidar com o agravo à saúde (Costa et al., 2016). O paciente, por sua vez, precisa acreditar que sua família continuará lhe fornecendo suporte espiritual, e que conta com uma rede de apoio, na qual encontrará conforto e força para lidar com a situação, e o ajudar a passar por este processo (Moreira-Almeida, Lotufo Neto \& Koenighg, 2006).

A família é o primeiro grupo social no qual o indivíduo está inserido e é considerada a unidade primária de cuidado, local onde o sujeito vive suas primeiras experiências interpessoais. Ela é caracterizada por ser um sistema intercomunicante e de relações de reciprocidade, ou seja, cada membro exerce influência sobre os outros, e qualquer mudança que ocorre com um componente afetará os demais. Deste modo, quando um membro familiar é acometido por uma enfermidade, isto faz com que ocorram modificações na vida de todos os envolvidos, de ordem afetiva, econômica e social (Costa et al., 2016).

\section{Sentimentos Diante da Cura}

A cura do câncer, para a entrevistada, ocorreu não somente em relação ao tratamento realizado, mas especialmente porque é uma pessoa muito espiritualizada e acredita em Deus e em Nossa Senhora do Caravaggio. Esta fé lhe diz que não está desamparada por Deus e que tudo vai passar no momento certo. A fé constitui-se, portanto, em um sentimento de confiança de que o indivíduo alcançará o seu desejo, um modo de pensar construtivo.

A espiritualidade faz parte da natureza humana, deve ser desvelada pela vivência e descobertas individuais, sendo que é aquilo que cada indivíduo acredita ser para si, podendo aparecer nas formas de propósito de vida, conexão com uma força/um algo maior, que lhe auxilia no autoconhecimento. A entrevistada, além de ser muito espiritualizada, conforme ela mesma se declara, tem uma religião, que é a Católica Apostólica Romana. 
Após curada do câncer, ela afirma que só agradece as bênçãos recebidas. Informa que pagou a promessa que havia feito á Santa por tê-la curado do câncer. No relato da entrevistada, Fé, espiritualidade e superação são as palavras que mais fazem parte de sua vida.

[...] A minha espiritualidade me dá tranquilidade, eu não tenho mais medo do sofrimento e da morte, etenho certeza que minha fé me salvou [...]

.[...] se eu não fosse tão forte na minha fé, na minha religião católica e em Nossa Senhora de Caravaggioeu não teria superado o câncer [...].

[...] como havia prometido paguei minha promessa a Nossa Senhora de Caravaggio, pois minha fé nela eem Deus me ajudaram a superar a doença [...].

No caso de Rosa, a sua espiritualidade, religião e fé auxiliaram no processo de cura e melhorou sua qualidade de vida durante o tratamento. Ela apegou-se em sua religião, na devoção e fé, que lhe deram muita satisfação e força suficiente para pensar na doença de um ângulo diferente.

A espiritualidade, a fé e a religião são fatores impares na saúde dela, e serviram de apoio para lidar com o câncer em seu processo de história da doença. Fazem parte de uma dimensão da pessoa, independentemente de sua identificação espiritual,cultural, religiosa ou outra (Balboni et al., 2014). A influência positiva da espiritualidade no prognóstico de pacientes portadores de doença crônica, com influência em diversos aspectos como a adesão ao tratamento, a reação frente ao diagnóstico e a manutenção da qualidade de vida ao longo do tratamento (Szaflarski, 2013).

Outras estratégias de enfrentamento como manter-se calmo, procurar não sofrer por antecipação e minimizar o problema, diminuindo a carga de estresse ocasionada por ele também são utilizadas por pacientes oncológicos (Oliveira et al., 2012). A religião é uma das possíveis formas de expressão da espiritualidade, não sendo, portanto, a única, já que em diferentes indivíduos existem diferentes compreensões e formas de entendê-la e expressá-la (Borba \& Weissheimer, 2011).

Frente a uma doença como o câncer, os pacientes procuram alternativas que os levam a enfrentar esta vivência tão avassaladora. Neste sentido, as crenças espirituais e religiosas oferecem suporte emocional, social e motivacional, além de promover estilos de vida mais saudáveis. Neste sentido, conhecer as crenças do paciente e seus familiares é fundamental para que o profissional de saúde compreenda suas necessidades (Costa et al., 2016).

A vivência de um câncer e de uma colostomia causa um impacto duplo na vida da pessoa. O primeiro é atribuído à incerteza da cura, à possibilidade da morte eminente e, num segundo momento, o impacto provoca a deterioração da imagem, a vergonha e o medo da rejeição (Cascais et al., 2007).

Estudos têm apontado para os aspectos positivos sobre crenças religiosas e espiritualidade na melhoria da qualidade de vida de pacientes com doenças graves. Indicam que pessoas religiosas têm menos depressão, maior suporte social, melhor saúde física e mental. Estar apoiado na fé e no suporte de uma religião leva o ser humano a experimentar maior bem-estar emocional, ter dignidade e paz interior, além da certeza de que será curado. A espiritualidade dá um significado para a vida.

Por meio de atitudes como caridade, oração, benevolência, amorosidade e muita fé, as pessoas espiritualizadas procuram um sentido de conexão com algo maior que si próprio. Isto pode ou não incluir uma participação religiosa formal. Ser espiritualizado num momento de dor, de enfrentamento de uma doença crônica e grave como o câncer ajuda na busca pelo sentido da vida e ameniza o sofrimento enfrentado. 


\section{Considerações Finais}

A partir da entrevista realizada com a paciente, observou-se que a fé e espiritualidade fortaleceram e auxiliaram a paciente a enfrentar a doença e o tratamento com mais resiliência. O estudo indica que a família e os amigos também foram essenciais na sua recuperação, na manutenção de sua qualidade de vida e bem-estar geral durante todo o processo da doença.

Rosa considera que sua fé a auxiliou durante toda a vida e no momento do diagnóstico do câncer foi crucial. Acredita que a sua crença e fé a curou. Para a paciente foi fundamental ter uma religião e se apoiar na espiritualidade para que pudesse seguir em frente durante o tratamento. Diz que esta experiência a tornou uma pessoa melhor e a auxiliou a perceber o que de fato é importante na vida.

Com este estudo de caso evidenciamos que uma pessoa espiritualizada, que crê em algo superior, consegue se sentir apoiada e fortalecida, nos períodos adversos da sua vida e, consegue superá-los. Os achados deste estudo, possibilitaram a compreensão de como é a experiência de conviver com o câncer colo retal, utilizando a espiritualidade, a religião e a fé como suporte. O caso de Rosa aponta que a religião e a espiritualidade foram fundamentais desde a revelação do diagnóstico, bem como suporte e estratégia de enfrentamento da doença e na sua percepção de cura. A família, a fé, e a espiritualidade foram fundamentais para a recuperação da paciente, pois o amor e a compreensão auxiliam em seu dia a dia e amenizam seu sofrimento.

Acredita-se que este estudo traga contribuição aos profissionais de saúde, familiares e os próprios pacientes, acometidos por doenças graves, sobre a relevância de encontrarem caminhos que possam os auxiliar ao longo da trajetória do tratamento da doença.

\section{Referências}

Aquino, V. V. \& Zago, M. M. F. (2007). O significado das crenças religiosas para um grupo de pacientes oncológicos em reabilitação. Revista LatinoAmericana de Enfermagem, 15(1):42-47.

Balboni, M. J, Puchalski, C. M \& Peteet, J. R. (2014). A relação entre medicina, espiritualidade e religião: três modelos de integração. Journal of Religion \& Health, 53(5).

Bardin, L. Análise de conteúdo. (2011). Edição 70.

Borba, P. F. \& Weissheimer, A. M. (2011). A influência da espiritualidade na saúde e na qualidade de vida dos indivíduos. In $31^{\text {a }}$ Semana Científica doHCPA. (pp. 48). Porto Alegre, RS. Anais de Resumos [...].HCPA.

Cascais, A. F. M. V., Martini, J. G. \& Almeida, P. J. S. (2007). O impacto da ostomia no processo de viver humano. Texto e Contexto: Enfermagem, 16(1):163167.

Costa, J. M., Finco, G. M., Souza, R. L. G., Medeiros, W. C. M. \& Melo, M. C. M. (2016). Repercussões biopsicossociais do diagnóstico de câncer colorretal para pacientes oncológicos. Revista da Sociedade Brasileira de Psicologia Hospitalar, 19(2):5-23.

Delgado-Guay \& Marvin, O. (2014). Espiritualidade e religiosidade nos cuidados de suporte e paliativos. Revista de Enfermagem UFPE Online, 8(3):308-313. Duarte-Franco, E \& Franco, E. L. (2004). Epidemiologia e fatores de risco em câncer colorretal. In Rossi, B. M. et al. Câncer de cólon, reto e ânus. (pp. 3-21). Lemar e Tecmedd Editora.

Gifford, W., Thomas, O., Thomas, R., Grandpierre, V. \& Ukagwu, C. (2019). Spirituality in cancer survivorship with First Nations people in Canada. Support Care Cancer, 27(8):2969-2976.

Instituto Nacional do Câncer - INCA. (2014). O que é câncer? INCA.

Leme, R. C. P., Pereira, K. G., Coutinho, F. G., Assis, B. R. \& Leme, M. B. P. L. (2007). Existe diferença no estadiamento entre doentes operados de câncer colorretal no sistema previdenciário e na clínica privada? Revista Brasileira do Colégio de Cirurgiões, 34(3):166-169.

Lima, C. P. \& Machado, M. A. (2018). Cuidadores Principais Ante a Experiência da Morte: Seus Sentidos e Significados. Psicologia: Ciência e Profissão,38(1):88-101.

Moreira-Almeida, A, Lotufo Neto, F. \& Koenighg, H. G. (2006). Religiosidade e saúde mental: uma revisão. Revista Brasileira de Psiquiatria, 28(3):242-250.

Oliveira, M., Oliveira, T. \& Schnaider, T. (2012). Autoestima, espiritualidade e depressão em pacientes portadores de neoplasia colorretal. Revista do Médico Residente, 14(4):1-10.

Penna, T. L. M. (2004). Dinâmica psicossocial de família de pacientes com câncer. In Mello Filho, J. \& Burd, M. (orgs). Doença e família. São Paulo, SP:Casa 
Research, Society and Development, v. 10, n. 10, e226101018604, 2021

(CC BY 4.0) | ISSN 2525-3409 | DOI: http://dx.doi.org/10.33448/rsd-v10i10.18604

do psicólogo.

Pinto, S, Caldeira, S. \& Martins, J. C. (2012). A espiritualidade nos pacientes com câncer em quimioterapia. CuidArte Enferm, 6(1):8-14.

Porto, A. O. (2004). Pacientes oncológicos: respostas emocionais frente a doença. Monografia (Graduação em Psicologia) - Centro Universitário de João Pessoa. João Pessoa, PB.

Salazar, O. M. \& Motta, N. W. D. (2001). Tumores Avançados: Epidemiologia, etiopatogenia, diagnóstico e estadiamento clínico. In: $1^{\circ}$ Seminário em Radiologia. (pp. 117-146). Angra dos Reis, RJ. Anais [...].INCA.

Silva, P. L. N. D., Ruas, P. R., Barbosa, H. A., Soares, L. M. \& Rocha, G. G. D. (2013). O significado do câncer: percepção de pacientes. Revista de Enfermagem UFPE online, 7(12):6828-6833.

Siqueira, H. D., Cecagno, D., Medeiros, A. C. D., Sampaio, A. D. \& Rangel, R. F. (2017). Espiritualidade no processo saúde-doença-cuidado do usuário oncológico: olhar do enfermeiro. Revista de Enfermagem UFPE online, 11(8):2996-3004.

Szaflarski, M. (2013). Espiritualidade e religião entre indivíduos infectados pelo HIV. HIV/AIDS atual. Reports, 10(4).

Turke, K. C., Canonaco, J. S., Artioli, T., Lima, M. S. D. S., Batle, A. R. et al. (2020). Depressão, ansiedade e espiritualidade em pacientes oncológicos.Revista da Associação Medica Brasileira, 66(7):960-965.

Vasconcelos, E. M. (2010). A associação entre vida religiosa e saúde: uma breve revisão de estudos quantitativos. Revista Eletrônica de Comunicação Informação \& Inovação em Saúde, 4(3):12-18.

Venâncio, J. L. (2004). Importância da atuação no tratamento de mulheres com câncer de mama. Revista brasileira de cancerologia, 50(1):55-63. Yin, R. K. (2001). Estudo de caso: planejamento e métodos. (2a ed.), Bookman.

Ventura, M.M. (2007). O Estudo de Caso como Modalidade de Pesquisa. Rev SOCERJ. 20(5):383-386 